Sharif University of Technology
Scientia Iranica
SCIENTIA
IRAN ICA
http://scientiairanica.sharif.edu

\title{
Performance of alkali activated slag concrete under aggressive environment
}

\author{
P. Kathirvel* and S.R.M. Kaliyaper umal \\ School of Civil Engineering, SASTRA University, Thanjavur - 613401, Tamilnadu, India.
}

Received 29 July 2016; received in revised form 7 November 2016; accepted 25 February 2017

\section{KEYWORDS}

Geopolymer concrete; Alkali activated slag; Aggressive environment;

Mechanical properties; Sulphate;

Chloride;

Ambient temperature.

\begin{abstract}
The environmental effects of production of Portland Cement (PC) have provoked the researchers to examine the growth of concrete with $100 \%$ replacement of cement with industrial byproducts containing high amounts of $\mathrm{Si}$ and $\mathrm{Al}$, which are activated by alkali solutions, termed geopolymer concrete. Concrete made with PC can be durable under mild exposure condition when properly designed, but it undergoes deterioration under severe exposure condition. Since very few works were performed on the ambient cured Alkali Activated Slag Concrete (AASC) under aggressive environmental condition, this work was intended to study the effect of binder content and sodium hydroxide concentration on AASC subjected to aggressive environment. In this regard, an experimental investigation was carried out to study the influence of chloride, acid, and sulphate environments on the physical and mechanical properties of AASC. The results show that the AASC mixes perform well under aggressive environment condition.
\end{abstract}

(C) 2018 Sharif University of Technology. All rights reserved.

\section{Introduction}

The manufacture of PC needs a huge amount of energy. Moreover, an immense sum of $\mathrm{CO}_{2}$ is transmitted to the atmosphere due to the calcination reaction during the manufacturing process. In the manufacture of $1 \mathrm{~T}$ $\mathrm{PC}, 0.53 \mathrm{~T} \mathrm{CO}_{2}$ is released due to the calcination, and it may increase to as much as $1 \mathrm{~T}$ if carbon gasoline is used as energy source. Conversely, the creation of commercial through-products releases fewer amounts of Green-House Gases (GHG). Fly ash produces 80$90 \%$ and slag produces $80 \%$ less GHG emission to the atmosphere than PC does. Therefore, $100 \%$ substitution of $\mathrm{PC}$ with fly ash or slag would significantly reduce the impact on environment. In cement concrete,

\footnotetext{
*. Corresponding author. Tel.: +914362 264101; Fax: +91 4362 264120

E-mail addresses: parthiban@civil.sastra.edu (P. Kathirvel); srm@civil.sastra.edu (S.R.M. Kaliyaperumal)
}

Calcium Silicate Hydrate (C-S-H) and the portlandite $\left(\mathrm{Ca}(\mathrm{OH})_{2}\right)$ are the main hydration products, which govern the strength and the binding characteristics, but make the concrete highly susceptible to chemical degradation when exposed to severe environmental conditions. Moreover, in some cases, the configuration may require to be revamped or even reinstated due to this effect. The dispersal of dissolved species inside interstitial fluid and dissolution of diverse hydrate phases were the two processes suggested by Xie et al. [1] to control the degradation of cement-based materials under chemical exposure. Yang and Cho [2] expressed that the accelerated chloride migration test showed a decent relationship linking the charge passed and the steady state chloride flux. However, a new method based on Neumann's theory was proposed by Wang et al. [3] to determine the chloride diffusion coefficient without the aid of electric current contrast to accelerate chloride permeability test or chloride migration test. Cement concrete subjected to sulphate exposure results in the chemical response of sulphate particles as the forceful agent to the aluminate segment of hardened 
cement paste [4,5]. The formation of ettringite due to high amount of $\mathrm{C}_{3} \mathrm{~A}$ is the main reason for the deterioration of PC [6]. Among the properties that control the resistance to sulphate exposure, permeability and chemical composition of cement paste are the most important. Due to the difference in the chemical and phase compositions, the concrete made with $\mathrm{PC}$ is more susceptible than that made with slag to acid attack. As a result of the formation of C-S-H gel and silica gel, the surface of the cement concrete specimens becomes soft and could be delaminated, resulting in deterioration of the concrete layers [7]. Alkali Activated Slag (AAS) mortar exposed to 5\% sulphuric acid shows severe degradation in comparison with citric acid, hydrochloric acid, and nitric acid solutions over a period of 6 months [8]. The concrete made with AAS has superior resistance to the concrete made with OPC of similar grade when reacted with acetic acid solution of $\mathrm{pH}=4$ [7].

Most of the previous studies have been carried out to investigate the behavior of geopolymer in the form of mortar under aggressive environment when cured under elevated temperature. Since very few researches were carried on geopolymer concrete under ambient temperature curing, this experimental investigation was carried out to study the effect of binder content and $\mathrm{NaOH}$ concentration on the physical and mechanical properties of AASC under aggressive environment.

This paper at the inception provides an outline of the experimental investigation into integrating materials and their characteristics, their proportioning, and the experimental mechanism. It is then pursued by an elaborated discussion of the obtained results, where the effects of addition of binder content (350, 400 , and $450 \mathrm{~kg} / \mathrm{m}^{3}$ ) and $\mathrm{NaOH}$ concentration (10, 12, and $14 \mathrm{M}$ ) on the physical and mechanical properties of the AASC under aggressive environment (acid, sulphate, and chloride) condition are explained. The properties are offered in conjunction with added significant elucidations.

\section{Materials and methods}

2.1. Constituent materials and mix proportion Ground Granulated Blast Furnace Slag (GGBFS) was used as Geopolymer Source Material (GSM); GGBFS is the most common cementitious material for AAS binder [9] and its chemical composition is given in Table 1.

From Table 1, the slag used was categorized as acidic as the ratio of the total basic to acidic components was found to be 0.98 , which made it best suited as a starting material for AAS binder. The past research work suggested that the blend of sodium hydroxide $(\mathrm{NaOH})$ and sodium silicate $\left(\mathrm{Na}_{2} \mathrm{SiO}_{3}\right)$ solution could be used as alkali activators resulting in higher strength [10]. Sodium hydroxide was acquired in the form of flakes and sodium silicate in liquid form with silica modulus of 2.5. The fine and coarse aggregates were equipped in accordance with ASTM C33/C33M (Standard Specification for Concrete Aggregates, ASTM International, 2016) and their moisture condition was found to be in Saturated Surface Dry (SSD) condition. Graded river sand with a fineness modulus of 2.56 and specific gravity of 2.58 was used as fine aggregate along with the coarse aggregate of $16 \mathrm{~mm}$ maximum size of crushed granite type available in saturated surface dry condition with a fineness modulus of 6.70 and specific gravity of 2.61. To evaluate the performance of the mixes under aggressive environment condition, the AASC mixes were prepared with variations in the volume of GGBFS with 350,400 , and $450 \mathrm{~kg} / \mathrm{m}^{3}$ and $\mathrm{NaOH}$ concentration with 10,12 , and 14 molars, keeping the molar ratio of $\mathrm{SiO}_{2} / \mathrm{Al}_{2} \mathrm{O}_{3}$ and liquid to binder constant; the mix proportions are shown in Table 2.

\subsection{Methodology}

The workability of the mixes was determined in the form of slump cone test following ASTM C143/C143M (Standard Test Method for Slump of Hydraulic-Cement Concrete, ASTM International, 2015). The compres-

Table 1. Chemical composition of GGBFS.

\begin{tabular}{ccccccccc}
\hline Oxide & $\mathbf{C a O}$ & $\mathbf{S i O}_{2}$ & $\mathbf{A l}_{\mathbf{2}} \mathbf{O}_{\mathbf{3}}$ & $\mathbf{M g O}$ & $\mathbf{S O}_{\mathbf{3}}$ & $\mathbf{F e}_{\mathbf{2}} \mathbf{O}_{\mathbf{3}}$ & $\mathrm{Na}_{\mathbf{2}} \mathbf{O}$ & $\mathbf{K}_{\mathbf{2}} \mathbf{O}$ \\
\hline GGBFS (\%) & 36.77 & 30.97 & 17.41 & 9.01 & 1.82 & 1.03 & 0.69 & 0.46 \\
\hline
\end{tabular}

Table 2. Mix proportioning of the AASC mixes.

\begin{tabular}{cccccc}
\hline \multirow{2}{*}{ Mix label } & $\begin{array}{c}\text { Slag } \\
\text { content }\end{array}$ & $\begin{array}{c}\text { Fine } \\
\text { aggregate }\end{array}$ & $\begin{array}{c}\text { Coarse } \\
\text { aggregate }\end{array}$ & $\begin{array}{c}\mathbf{N a O H} \\
\text { solution }\end{array}$ & $\begin{array}{c}\mathrm{Na}_{2} \mathrm{SiO}_{3} \\
\text { solution }\end{array}$ \\
\cline { 2 - 6 } & \multicolumn{5}{c}{ Mix proportions } \\
$\left.\mathbf{( k g} / \mathbf{m}^{\mathbf{3}}\right)$ \\
\hline AAS350 & 350 & 450 & 1422 & 58.33 & 116.67 \\
AAS400 & 400 & 432 & 1368 & 66.67 & 133.33 \\
AAS450 & 450 & 415 & 1313 & 75 & 150 \\
\hline
\end{tabular}


sive strength was determined using cylindrical specimens of the size $100 \mathrm{~mm}$ in diameter and $200 \mathrm{~mm}$ in height as per ASTM C39/C39M ( Standard Test Method for Compressive Strength of Cylindrical Concrete Specimens, ASTM International, 2015). The moisture absorption and volume of voids were ascertained using cubes $100 \mathrm{~mm}$ in size as per ASTM C642 (Standard Test Method for Density, Absorption and Voids in Hardened Concrete, ASTM International, 2013). Exposure to acid attack was chosen to study the durability characteristics as the acids are normally considered to be highly aggressive to concrete. Sulphuric acid was taken into account as it combined both acidic and sulphate environments. The percentage variations of mass and compressive strength of the mixes made with $100 \mathrm{~mm}$ cubes exposed to $2 \%$ sulphuric acid over a period of 90 days were assessed as considered by $\mathrm{Li}$ and Zhao [11]. The chloride ion diffusion was measured using salt ponding test similar to the test prescribed in AASHTO T259 (Standard Method of Test for Resistance of Concrete to Chloride Ion Penetration (Salt Ponding Test), American Association of State Highway and Transportation Officials, 2002) and AASHTO T260 (Standard Method of Test for Sampling and Testing for Chloride Ion in Concrete and Concrete Raw Materials, American Association of State Highway and Transportation Officials, 2009) using cylindrical specimens of $100 \mathrm{~mm}$ diameter and $200 \mathrm{~mm}$ height, and potentiometric titration was carried out as per NT BUILD 208 (Concrete, hardened: Chloride content by Titration, Nord Test Method, 3rd Edn., 2011) to determine the total chloride content (\%) by weight of concrete using Eq. (1):

$$
\text { Total chloride content }\left(\mathrm{Cl}^{-}\right)=3.545 x \frac{V_{1} N_{1}-V_{2} N_{2}}{m}
$$

where, $V_{1}$ and $N_{1}$ are the volume and normality of $\mathrm{AgNO}_{3}$ solution added, respectively, and $V_{2}$ and $N_{2}$ are the volume and normality of ammonium thiocyanate added, respectively.

The resistance to sulphate attack was evaluated using cylindrical specimens of size $100 \mathrm{~mm}$ in diameter and $200 \mathrm{~mm}$ in height following ASTM C88 (Standard Test Method for Soundness of Aggregates by use of Sodium Sulfate or Magnesium Sulfate, ASTM International, 2013). The specimens were immersed in $5 \%$ sodium and magnesium sulphate solutions over a period of 90 days and the reduction in mass and strength was evaluated. The core samples of $50 \mathrm{~mm}$ height were taken for visual examination. The solutions were changed periodically at an interval of 10 days in order to maintain the concentration throughout the exposure period. The loss in the strength was measured by Sulphate Deterioration Factor (SDF), which is the variation ratio percentage of the strength of the specimens after immersion in sulphate solution to that of the specimens immersed in water at age " $t$ ".

\section{Results and discussion}

\subsection{Fresh concrete properties}

The workability of concrete is mainly influenced by the water requirements at the time of mixing. For conventional concrete, it was decided mainly on the basis of the maximum size of aggregate used. The test results of the workability of the AASC mixes are presented in Figure 1. As can be seen, the workability of AASC mixes decreased when $\mathrm{NaOH}$ concentration increased. A reason for this pattern can be the measure of water and alkaline in the solution prepared. More $\mathrm{NaOH}$ solids were allowed with increase in the activator concentration and less free water for a given volume, bringing about the reduction in the slump values. Similarly, the slump values were observed to decrease with increase in the GGBFS volume similar to OPC concrete.

\subsection{Compressive strength}

The compressive strength results of the AASC mixes at the age of 7 and 28 days of curing are shown in Figures 2 and 3, respectively. The use of high calcined source material as binder was stated to improve the

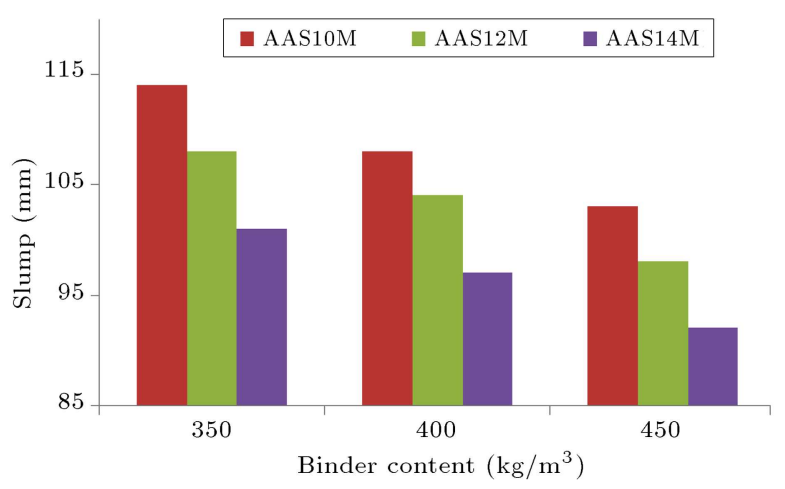

Figure 1. Workability results of the AASC mixes.

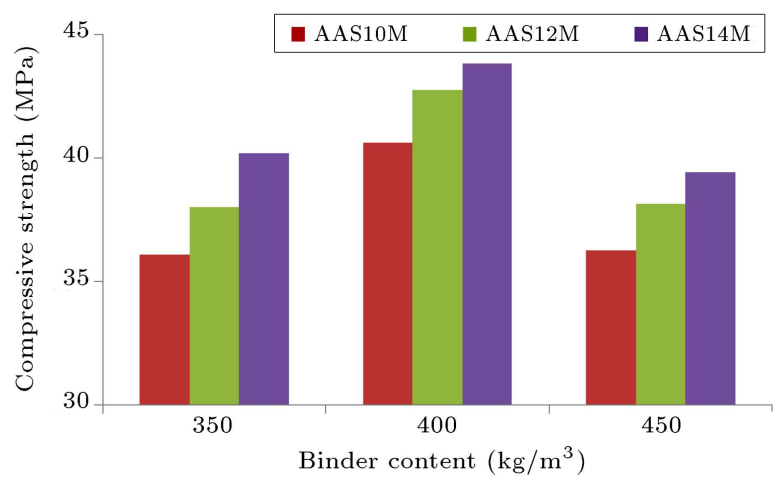

Figure 2. 7-day compressive strength results of the AASC mixes. 


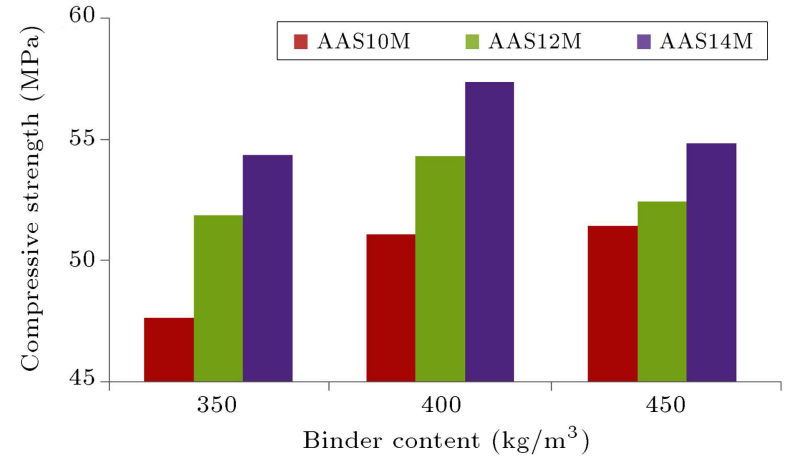

Figure 3. 28-day compressive strength results of the AASC mixes.

microstructure of the geopolymer matrix resulting in high strength [12], and reaction between GGBFS and alkaline solution was an exothermal process in which the geopolymerization process would be promoted by the generated heat [13]. GGBFS contains higher $\mathrm{CaO}$ content and, consequently, it is a good impending resource of soluble $\mathrm{Ca}$ in the mixture. The amount of soluble calcium relies on the GGBFS quantity available in the mix and the compressive strength has a direct impact on it. The increase in the compressive strength results was found to be averagely $12.9 \%$ for 7 days and $11.8 \%$ for 28 days of curing with increase in the GGBFS content from 350 to $400 \mathrm{~kg} / \mathrm{m}^{3}$, and the drop was averagely $3.8 \%$ for 7 days and $3.4 \%$ for 28 days of curing when the GGBFS content increased to $450 \mathrm{~kg} / \mathrm{m}^{3}$.

The activator concentration is known as the most critical component influencing the properties of alkaliactivated binders. The impacts of activator concentration, in any case, are not generally that basic. While a few studies propose that a base minimum concentration of activators is required for the activation to be successful, there are distinctive studies demonstrating adverse impacts of high concentration on the strength properties of alkali-activated binders. The utilization of high concentration $\mathrm{NaOH}$ solution increases the dissolution of the solid materials and the geopolymerization process resulting in higher compressive strength mostly because of the higher level of leaching of $\mathrm{Si}$ and $\mathrm{Al}$. $\mathrm{NaOH}$ concentration on aqueous phases increases the compressive strength averagely by $13.0 \%$ and $12.9 \%$ for 7 and 28 days of curing, respectively, with increase in the $\mathrm{NaOH}$ concentration from $10 \mathrm{M}$ to $12 \mathrm{M}$ and further increases the strength averagely by $11.5 \%$ and $12.1 \%$ for 7 and 28 days of curing, respectively, from $12 \mathrm{M}$ to $14 \mathrm{M}$. Since one of the fundamental strides of geopolymerization procedure is the breakdown of aluminosilicate bonds (Si-O-Si and Al-O-Si) in alkaline environment, higher concentration prompts enhanced breakdowns. With more breakdown of aluminosilicate bonds, there are further prospects for hydrates to be shaped and, thus, increase in the compressive strength. The increase in the compressive strength with increase in $\mathrm{NaOH}$ concentration can be related to improved solvency of aluminosilicate at higher concentrations $[14,15]$.

\subsection{Saturated water absorption and volume of voids}

Variations of water absorption and the volume of voids of the AASC mixes are shown in Figures 4 and 5, respectively. The amount of binder content in concrete has especially strong impact on the water retention properties of AASC mixes, despite the fact that the absorption characteristics are, in all cases, lower than those of the equivalent OPC mixes of comparable porosities. This is most likely a consequence of the presence of exceptionally refined, convoluted, and confined porosity in the AASC samples into which water does not promptly infiltrate. Furthermore, the reaction products are continuously arranged at advanced ages of curing [16].

The superior property of the volume of voids is mainly because the structure of the $\mathrm{C}-\mathrm{A}-\mathrm{S}-\mathrm{H}$ ( $\mathrm{CaO}-$ $\left.\mathrm{Al}_{2} \mathrm{O}_{3}-\mathrm{SiO}_{2}-\mathrm{H}_{2} \mathrm{O}\right)$ binding gel type, which dominates the microstructure of the geopolymer concrete, is highly dense [17] compared to N-A-S-H $\left(\mathrm{Na}_{2} \mathrm{O}-\mathrm{Al}_{2} \mathrm{O}_{3^{-}}\right.$ $\left.\mathrm{SiO}_{2}-\mathrm{H}_{2} \mathrm{O}\right)$ gel formed in fly ash based GPC and C-S-H gel [18] formed in conventional cement concrete. The existence of added bound water, proved by the avail-

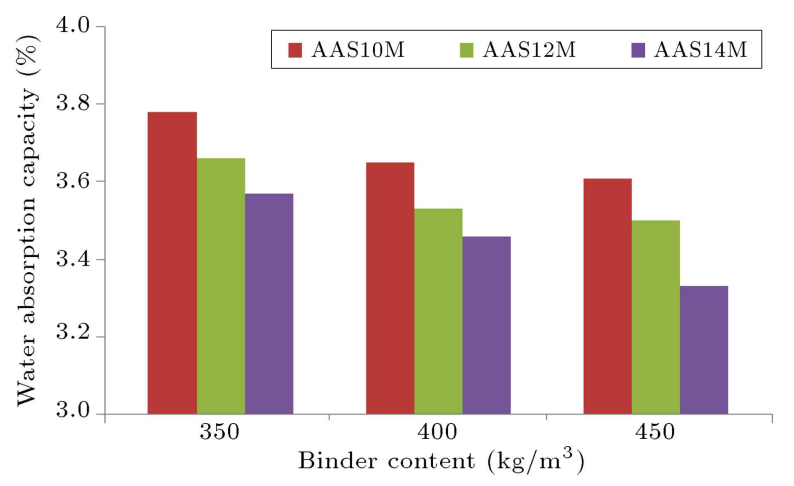

Figure 4. Water absorption capacity results of the AASC mixes.

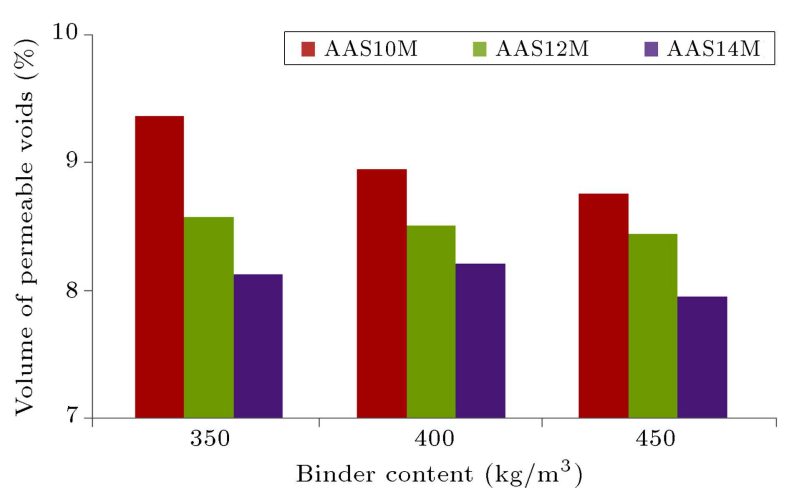

Figure 5. Volume of permeable voids results of the AASC mixes. 
ability of calcium ion in the network, offers superior pore-filling ability of C-A-S-H gel to N-A-S-H type gels in GPC [19].

\subsection{Resistance to sulphate attack}

\subsubsection{Sulphuric acid attack}

The reduction percentages in mass and compressive strength results are shown in Figures 6 and 7, respectively. The excellent acid resistance performance is mainly due to the absence of $\mathrm{Ca}(\mathrm{OH})_{2}$. Unlike the concrete made with $\mathrm{PC}$, which relies on C-S-H bonds for structural integrity, geopolymers are novel binders that depend on aluminosilicate for structural integrity and, hence, reported to be acid resistant. High content of binder leads to reduction in deterioration of specimens and is structurally intact with no appreciable change in colour. This excellent performance may also be associated with the formation of alumino-silicate gel as the main binder in AASC mixes, which generally does not have free lime [7]. Greater resistance of GPC to sulphuric acid in general has been stated by Thokchom et al. [20].

The AASC specimens are found to remain structurally intact without any significant variation in mass and compressive strength. Even after 90 days, the AASC specimens are structurally sound without any surface deterioration.

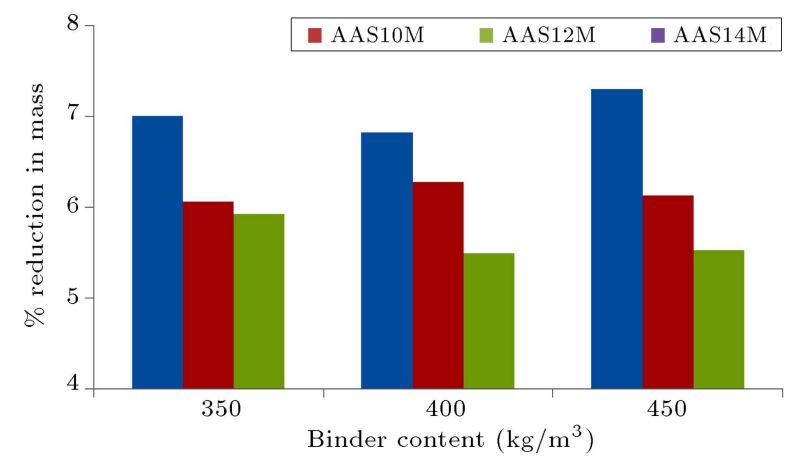

Figure 6. Variation in mass loss of the AASC mixes under $\mathrm{H}_{2} \mathrm{SO}_{4}$ attack.

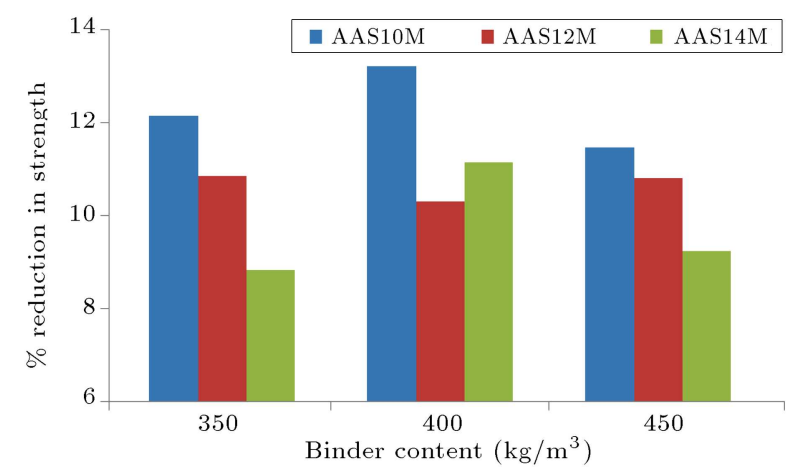

Figure 7. Variation in strength loss of the AASC mixes under $\mathrm{H}_{2} \mathrm{SO}_{4}$ attack.

\subsubsection{Sodium and magnesium sulphate attack}

The variation percentages in mass loss and strength loss of the AASC mixes after exposure to $5 \% \mathrm{Na}_{2} \mathrm{SO}_{4}$ solutions are shown in Figures 8 and 9, respectively, and those of AASC mixes under $\mathrm{MgSO}_{4}$ exposure are shown in Figures 10 and 11, respectively. The maximum reduction in the mass of the AASC mixes was found to be $2.54 \%$ and $4.57 \%$ under $\mathrm{Na}$ and $\mathrm{Mg}$ sulphate solutions, respectively, and that of the compressive strength was observed to be $8.06 \%$ and $13.15 \%$, respectively. Some of the past researches [2123 ] showed that there was a gain in the mass of the specimens under $\mathrm{Na}$ sulphate solution, whereas the

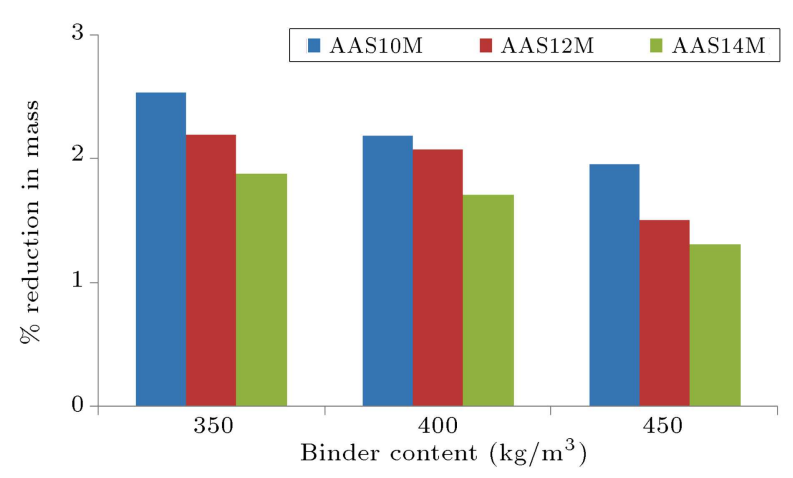

Figure 8. Variation in mass loss of the AASC mixes under $\mathrm{Na}_{2} \mathrm{SO}_{4}$ attack.

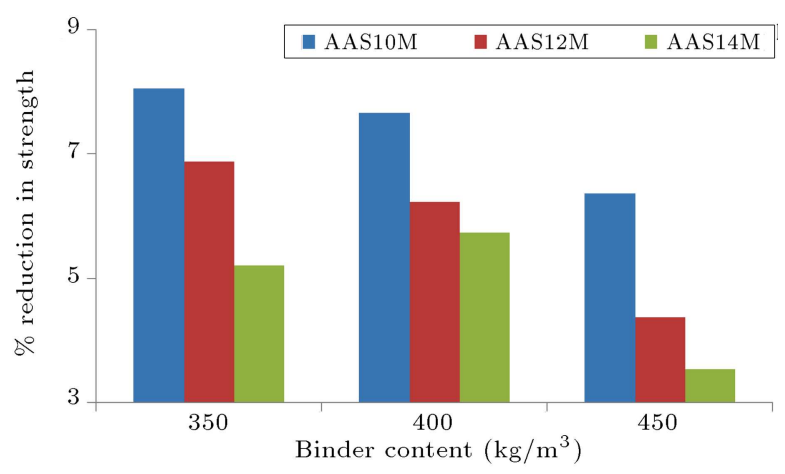

Figure 9. Variation in strength loss of the AASC mixes under $\mathrm{Na}_{2} \mathrm{SO}_{4}$ attack.

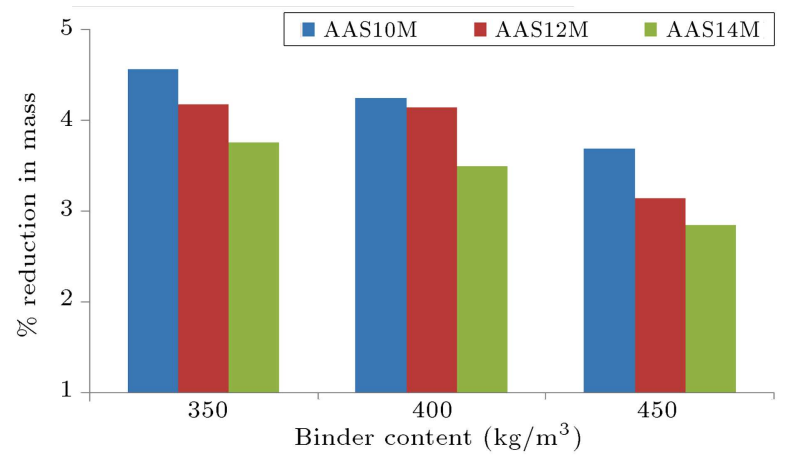

Figure 10. Variation in mass loss of the AASC mixes under $\mathrm{MgSO}_{4}$ attack. 


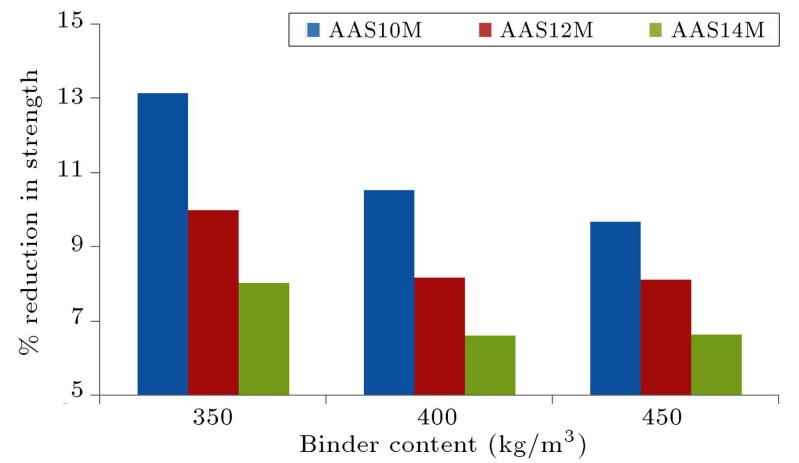

Figure 11. Variation in strength loss of the AASC mixes under $\mathrm{MgSO}_{4}$ attack.

present investigation shows a slight reduction in the mass under $\mathrm{Na}$ sulphate environment. This may be due to the ambient curing condition followed in this work, unlike elevated curing techniques adopted in the past researches, where the liquid present in the pores will be evaporated leaving the pores to be filled by the sulphate attacking agents resulting in mass gain [23]. The gain in the mass is also associated with the expansion of the specimens when the pores are filled with sulphate attacking agents like gypsum and ettringite [24].

It has been noted that the reduction percentage in mass and compressive strength decreases with increase in the $\mathrm{NaOH}$ concentration. High concentration of $\mathrm{NaOH}$ might be the reason for the arrangement of increasing amount of dense sodium-alumino-silicate gel in the network and rate of geopolymerization, and thereby, improved performance. The absence of Gypsum and Ettringite results in no significant reduction in mass loss and strength degradation of the AASC mixes. The specimens were found to maintain their integrity with no distress observed on the surface when examined visually. The specimens were subjected to increased amount of distress in $\mathrm{MgSO}_{4}$ solution compared to $\mathrm{Na}_{2} \mathrm{SO}_{4}$ solution. After 90 days of exposure, some cracks on the corners were observed and the degradation might be due to the presence of Gypsum and the release of alkalis from geopolymers into the solution in AASC. No formation of ettringite was observed as the slag was rich in aluminum not in the form available for the reaction.

Figure 12 shows the exposed specimens under $\mathrm{Na}$ and $\mathrm{Mg}$ sulphate environments after 90 days. The variation percentage in mass of the AASC specimens exposed to sodium and magnesium sulphate solutions is negligible. However, this cannot be taken as a reliable sign of deterioration by sulphate attack. Conversely, a considerable reduction in the compressive strength was observed with the sulphate exposure, which could be taken as a measurable indicator of deterioration. The specimens immersed in $\mathrm{Na}_{2} \mathrm{SO}_{4}$ solution showed exposition of grains alone, whereas the specimens in $\mathrm{MgSO}_{4}$ solutions showed both exposition and dissolved

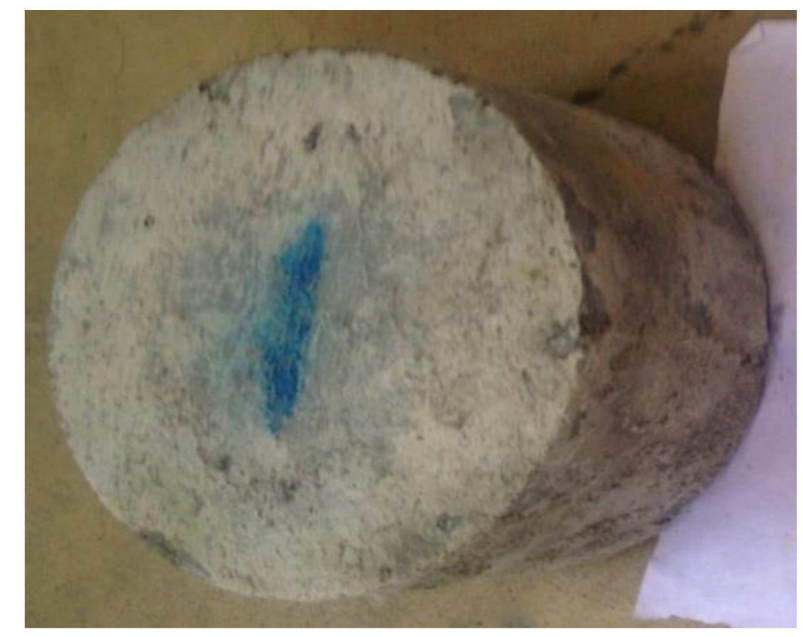

(a)

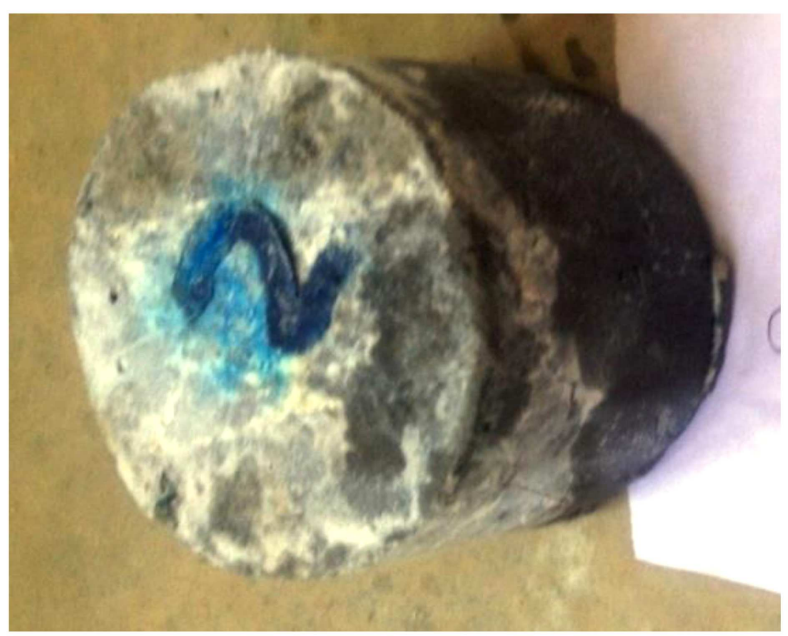

(b)

Figure 12. (a) Specimens subjected to $\mathrm{Na}_{2} \mathrm{SO}_{4}$ exposure. (b) Specimens subjected to $\mathrm{MgSO}_{4}$ exposure.

aluminosilicate matrix, which implied the rigorousness of $\mathrm{Mg}$ ions [25].

\subsection{Chloride penetration}

3.5.1. Chloride content profile

Various strategies are available to assess the chloride ion diffusion in OPC concrete. An electrical field is frequently offered to drive the chloride ion transportation in the samples. At the point where these techniques are utilized to assess the geopolymer frameworks, the electrical potential is required to accelerate the ion transportation through the pore system because of increased $\mathrm{Na}^{+}$concentration present in the pore arrangement [26]. Therefore, the chloride diffusion mechanism can be affected altogether. In this way, the accelerated tests are viewed as temperamental when contrasting frameworks and generously diverse pore arrangements [27]. The long-term investigation of chloride ion penetration in AASC mixes as the accelerated methods has been proved to be futile, since 
the rise in temperature of the geopolymer specimens during exhibition of the test is against the Ohm's law [28]. Salt ponding technique can be used to assess the chloride ion penetration under non-accelerated conditions as per ASTM C1202 (Standard test method for electrical indication of concrete's ability to resist chloride ion penetration, ASTM International, 2008). The chloride content profiles of the AASC mixes are shown in Figures 13 to 15 .

In the figures, it is observed that the reduced absorption capacity of the AASC mixes is mainly due to the high tortuous nature of the aluminosilicate phase of AASC in comparison with the porous microstructure of fly ash based geopolymer mixes [19]. The reason for the reduced porosity and pore sizes as well as improved tortuosity has been provided above. Chloride ingression can also be further reduced with the extended age of curing [27] due to reduced permeability and sorptivity. The results reveal that the increase in the $\mathrm{NaOH}$ concentration reduces the chloride ion diffusion. The increase in the $\mathrm{NaOH}$ concentration leads to increase in the compressive strength of geopolymer mixes due to dense matrix, thereby reducing the porosity, resulting in less chloride ingression. Generally, alkali with high concentration dissolves high proportion of source material due to higher degree of geopolymerization, resulting in dense microstructure of the system, thereby reducing the chloride ion ingression in AASC mixes with higher $\mathrm{NaOH}$ concentration. In general, the mixes made with AAS have almost zero $\mathrm{Ca}(\mathrm{OH})_{2}$ [29] and pores of lower size than OPC result in lower permeability, thereby preventing the ingress of deleterious ions.

\subsubsection{Chloride diffusion coefficient $\left(D_{c}\right)$}

The chloride profile from the tested specimens was used to compute the Chloride Diffusion Coefficient (CDC) and the results are provided in detail in Table 3 . In the present study, the chloride Diffusion coefficient $\left(D_{c}\right)$ has been computed using Fick's second law of diffusion, which is given by Eq. (2):

$$
\frac{\partial c}{\partial t}=D_{c} \frac{\partial^{2} C}{\partial x^{2}}
$$

where, $C$ is the concentration of chloride ions as a function of distance $x$, at any time $t$, and $D_{c}$ is the diffusion coefficient.

Table 3. Chloride Diffusion Coefficient (CDC) results of the AASC mixes.

\begin{tabular}{cccc}
\hline \multirow{2}{*}{$\begin{array}{c}\text { Slag content } \\
\left(\mathbf{k g} / \mathbf{m}^{\mathbf{3}}\right)\end{array}$} & \multicolumn{3}{c}{$\begin{array}{c}\text { Chloride diffusion coefficient } \\
\text { in } \mathbf{~ m}^{\mathbf{2}} / \mathbf{s}\left(\times \mathbf{1 0}^{-\mathbf{1 2}}\right)\end{array}$} \\
\cline { 2 - 4 } & $\mathbf{A A S 1 0 M}$ & $\mathbf{A A S 1 2 M}$ & $\mathbf{A A S 1 4 M}$ \\
\hline 350 & 2.64 & 1.84 & 1.61 \\
400 & 1.81 & 1.57 & 0.88 \\
450 & 1.56 & 0.91 & 0.80 \\
\hline
\end{tabular}

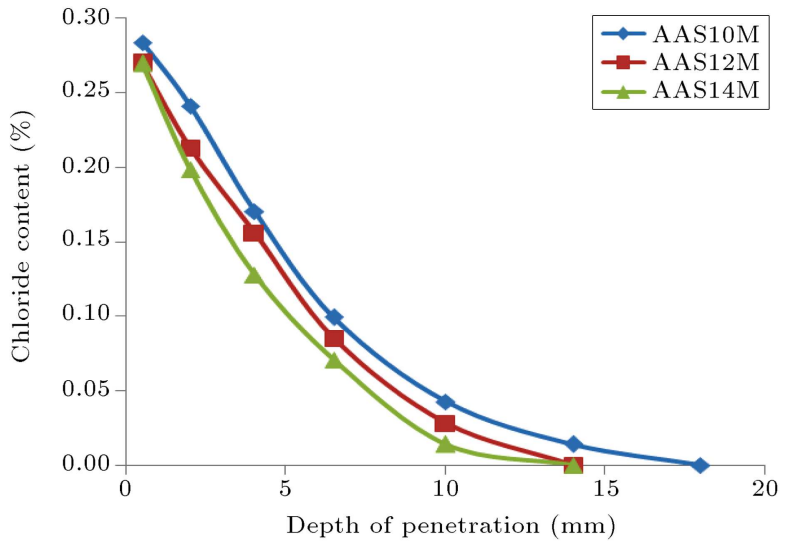

(a) Slag content $=350 \mathrm{~kg} / \mathrm{m}^{3}$

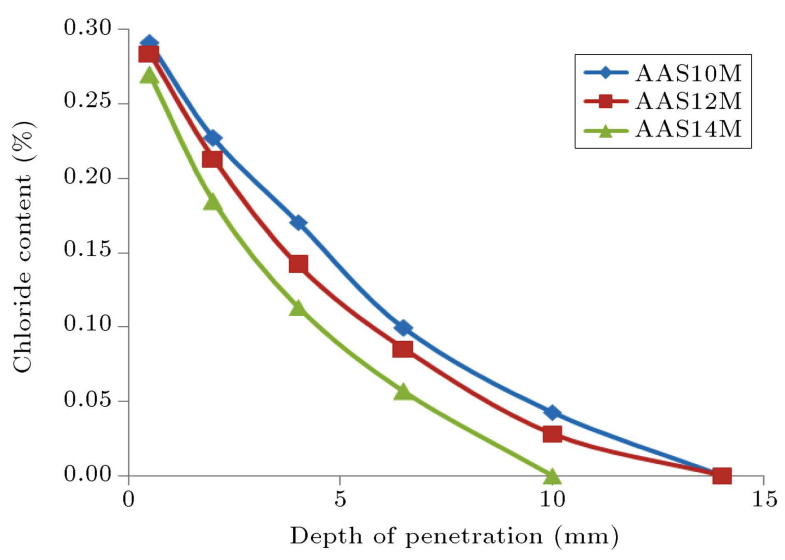

(b) Slag content $=400 \mathrm{~kg} / \mathrm{m}^{3}$

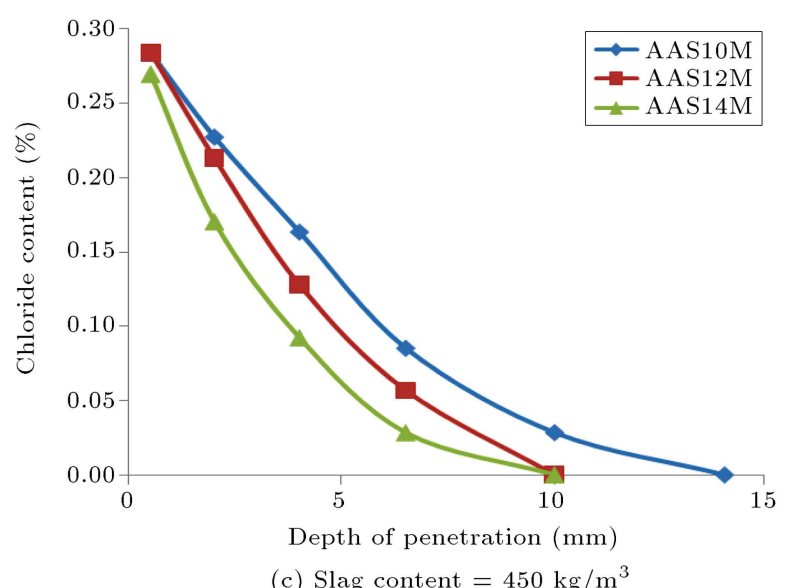

Figure 13. Chloride content profile for the AASC mixes with $L / B=0.45$.

This is helpful in predicting the time required for protecting the concrete from corrosion presuming a threshold rate in depassivating the steel reinforcement and, thereby, the initiation of corrosion. The CDC values are found to decrease with increase in the $\mathrm{NaOH}$ concentration and slag content. The improved resistance to chloride penetration is mainly due to the refined pore structure, which confines the diffusion of 


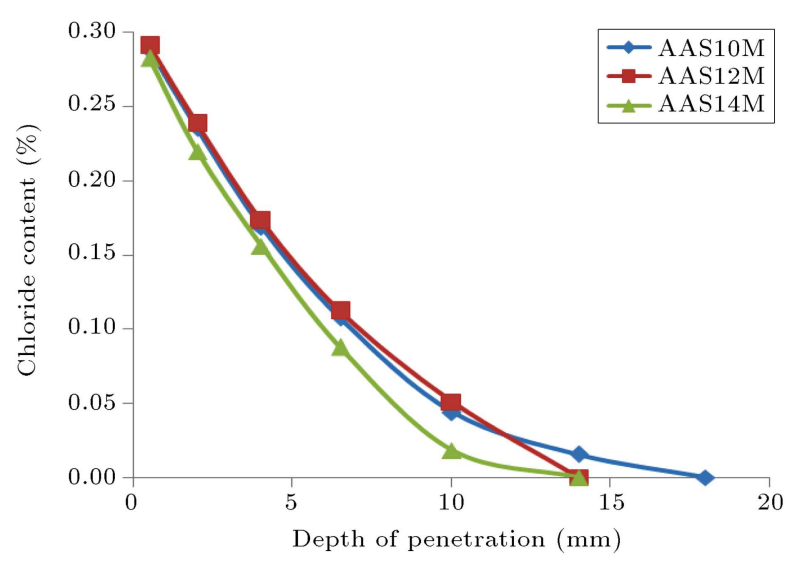

(a) Slag content $=350 \mathrm{~kg} / \mathrm{m}^{3}$

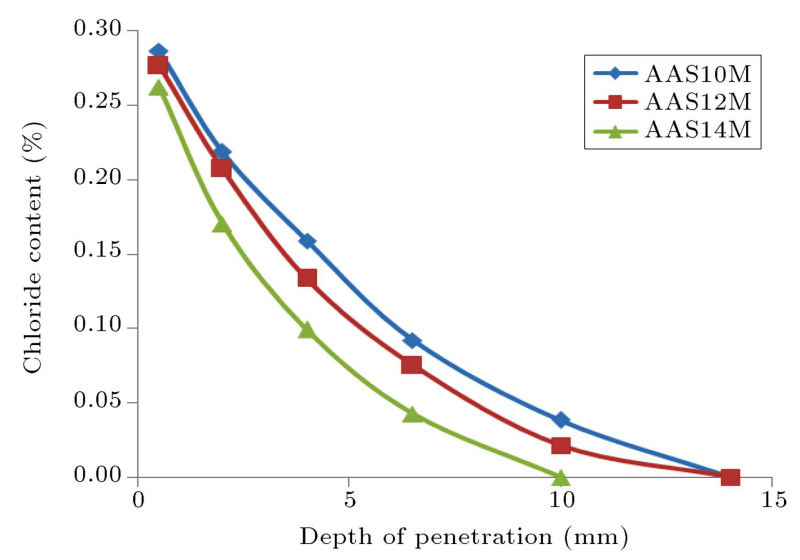

(b) Slag content $=400 \mathrm{~kg} / \mathrm{m}^{3}$

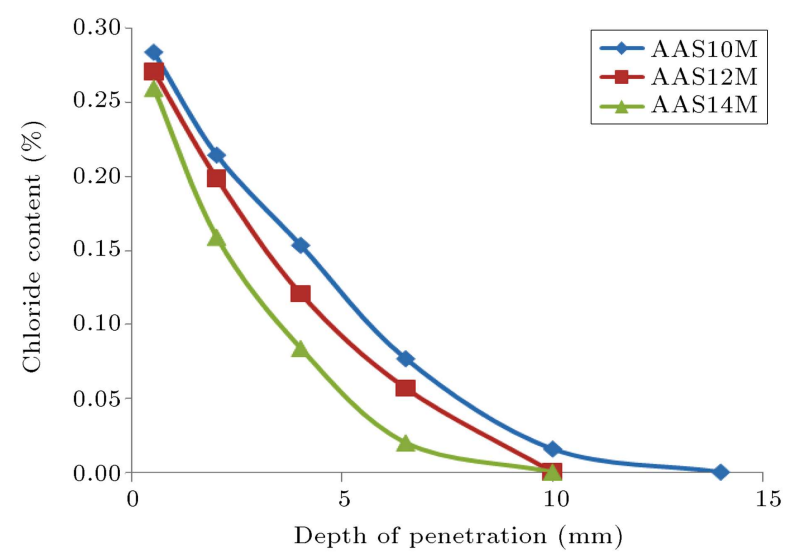

(c) Slag content $=450 \mathrm{~kg} / \mathrm{m}^{3}$

Figure 14. Chloride content profile for the AASC mixes with $L / B=0.50$.

chloride ions into the samples [30]. The CDC values are also observed to get reduced with increase in the slag content. This is due to the high refinement of pore microstructure with increased amount of slag content, thereby reducing the ingress of aggressive agents. Due to the very low CDC values for AASC mixes, it can be accepted that the time required for depassivation of steel in AASC is higher than that for cement concrete.

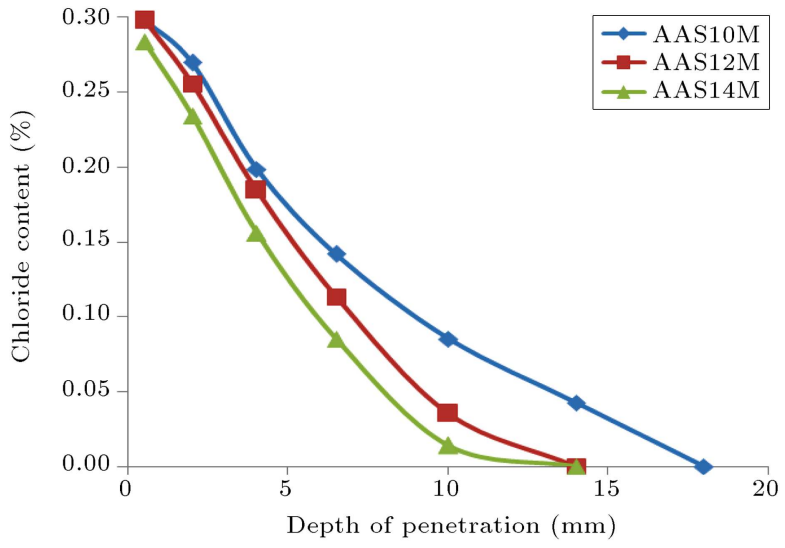

(a) Slag content $=350 \mathrm{~kg} / \mathrm{m}^{3}$

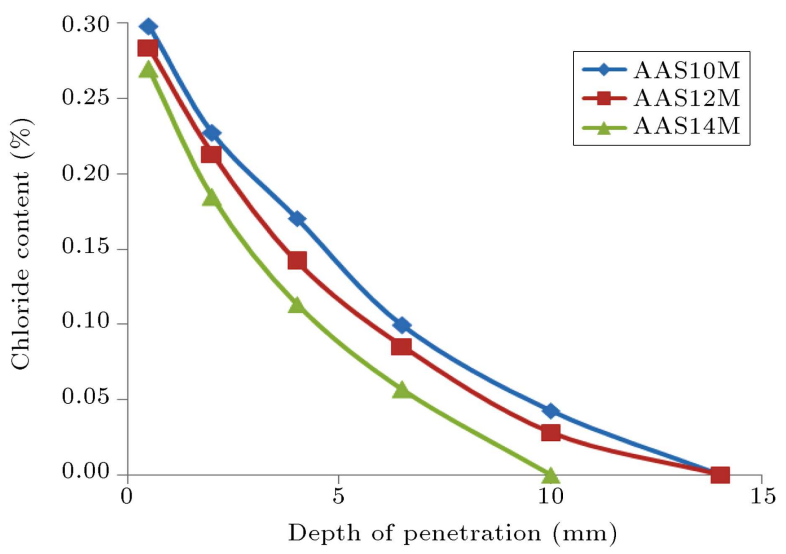

(b) Slag content $=400 \mathrm{~kg} / \mathrm{m}^{3}$

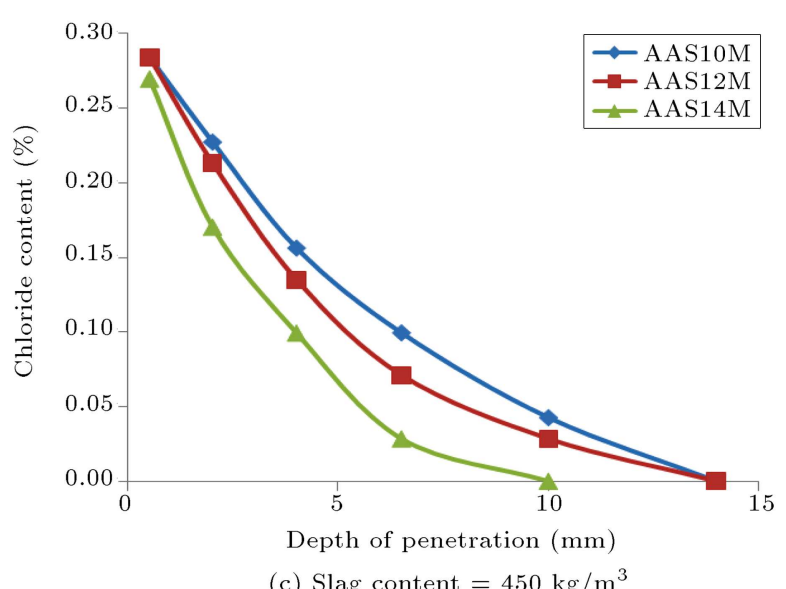

Figure 15. Chloride content profile for the AASC mixes with $L / B=0.55$.

\section{Conclusions}

By analyzing the concrete mixes prepared at a range of sodium hydroxide concentration and binder content, using alkali activated slag as binder, the mechanical properties and behavior under aggressive environment were determined. From the experimental results obtained, the following conclusions can be made: 
1. The compressive strength of the AASC mixes increases with increase in the $\mathrm{NaOH}$ concentration;

2. The AASC mixes show superior mechanical and durability properties under aggressive environment;

3. Rare evident for microcracking was observed in AASC mixes even at higher binder contents, which was mainly due to the low amount of heat release in AASC mixes compared to OPC mixes;

4. The performance of the AASC mixes was also improved with increase in the $\mathrm{NaOH}$ concentration, which was mainly because of improved polymerization products at higher concentrations;

5. The excellent resistance of the AASC mixes under acid environment was mainly due to the very low calcium oxide content and that of the sulphate environment was mainly due to the absence of sulphate deteriorating factors;

6. The reduced pore size and improved tortuous nature of AAS confined the diffusion of chloride ions into the samples;

7. In general, the mixes made with AAS have almost zero calcium hydroxide and pores of lower size than OPC result in lower permeability, protecting the concrete from the ingress of deleterious ions.

\section{Acknowledgement}

The authors acknowledge the Vice Chancellor of SASTRA University, Thanjavur, India, for providing the facilities to carry out the work and the encouragement in completing it.

\section{References}

1. Xie, S.Y., Shao, J.F., and Burlion, N. "Experimental study of mechanical behaviour of cement paste under compressive stress and chemical degradation", Cem. Concr. Res., 38(12), pp. 1416-1423 (2008).

2. Yang, C.C. and Cho, S.W. "The relationship between chloride migration rate for concrete and electrical current in steady state using the accelerated chloride migration test", Mater. Struct., 37, pp. 456-463 (2004).

3. Wang, C.H., Tsai, C.L., and Lin, C.C. "Penetration lag of chloride diffusion through concrete plate based on advancing model", J. Mar. Sci. Tech., 19(2), pp. 141-147 (2011).

4. Rasheeduzzafar, Dakhil, F.H., Al-Gahrani, A.S., AlSaadoun, S.S., and Bader, M.A. "Influence of cement composition on the corrosion of reinforcement and sulfate resistance of concrete", ACI Mater. J., 87(2), pp. 114-122 (1990).

5. Rasheeduzzafar, Al-Amoudi, O.S.B., Abduljanwad, S.N., and Maslehuddin, M. "Magnesium- sodium sulfate attack in plain and blended cements", J. Mater. Civil. Eng., 6(2), pp. 201-222 (1994).
6. Gollop, R.S. and Taylor, H.F.W. "Microstructural and microanalytical studies of sulfate attack: I. Ordinary Portland cement paste", Cem. Concr. Res., 22(6), pp. 1027-1038 (1992).

7. Bakharev, T., Sanjayan, J.G., and Chen, Y.B. "Resistance of alkali-activated slag concrete to acid attack", Cem. Concr. Res., 33(10), pp. 1607-1611 (2003).

8. Jiang, W., Silsbee, M.R., Breval, E., and Roy, D.M. "Alkali activated cementitious materials in chemically aggressive environments", In Mechanisms of Chemical Degradation of Cement-Based Systems, K.L. Scrivener and J.F. Young, E \& FN Spon, London (1997).

9. Wang, S.D. and Scrivener, K.L. "Hydration products of alkali activated slag cement", Cem. Concr. Res., 25(3), pp. 561-571 (1995).

10. Yang, K.H., Song, J.K., Ashour, A.F., and Lee, E.T. "Properties of cementless mortars activated by sodium silicate", Constr. Build. Mater., 22(9) pp. 1981-1989 (2008).

11. Li, G. and Zhao, X. "Properties of concrete incorporating fly ash and ground granulated blast-furnace slag", Cem. Concr. Compos., 25(3), pp. 293-299 (2003).

12. van Jaarsveld, J.G.S., van Deventer, J.S.J., and Lukey, G.C. "The effect of composition and temperature on the properties of fly ash- and kaolinite-based geopolymers", Chem. Eng. J., 89(1-3), pp. 63-73 (2002).

13. Ridtirud, C., Chindaprasirt, P., and Pimraksa, K. "Factors affecting the shrinkage of flyash geopolymers", Int. J. Miner. Metall. Mater., 18(1), pp. 100104 (2011).

14. Bondar, D., Lynsdale, C.J., Milestone, N.B., Hassani, N., and Ramezanianpour, A.A. "Engineering properties of alkali-activated natural Pozzolan concrete", $A C I$ Mater. J., 108(1), pp. 64-72 (2011).

15. Khale, D. and Chaudhary, R. "Mechanism of geopolymerization and factors influencing its development: A review", J. Mater. Sci., 42(3), pp. 729-746 (2007).

16. Bernal, S.A., Provis, J.L., de Gutierrez, R.M., and Rose, V. "Evolution of binder structure in sodium silicate-activated slag-metakaolin blends", Cem. Concr. Compos., 33(1), pp. 46-54 (2011).

17. Ismail, I., Bernal, S.A., Provis, J.L., San Nicolas, R., Hamdan, S., and van Deventer, J.S.J. "Modification of phase evolution in alkali-activated blast furnace slag by the incorporation of fly ash", Cem. Concr. Compos., 45, pp. 125-135 (2014).

18. Lothenbach, B., Scrivener, K., and Hooton, R.D. "Supplementary cementitious materials", Cem. Concr. Res., 41(12), pp. 1244-1256 (2011).

19. Provis, J.L., Myers, R.J., White, C.E., Rose, V., and van Deventer, J.S.J. "X-ray microtomography shows pore structure and tortuosity in alkali-activated binders", Cem. Concr. Res., 42(6), pp. 855-864 (2012). 
20. Thokchom, S., Ghosh, P., and Ghosh, S. "Effect of $\mathrm{Na}_{2} \mathrm{O}$ content on durability of geopolymer mortars in sulphuric acid", Int. J. Recent Trends Eng., 1, pp. 3640 (2009).

21. Justnes, H. "Thaumasite followed by sulphate attack on mortar with limestone filler", Cem. Concr. Compos., 25(8), pp. 955-959 (2003).

22. Santhanam, M., Cohen, M.D., and Olek, J. "Effects of gypsum formation on the performance of cement mortars during external sulphate attack", Cem. Concr. Res., 33(3), pp. 325-332 (2003).

23. Thokchom, S., Ghosh, P., and Ghosh, S. "Performance of fly ash based geopolymer mortars in sulphate solution", J. Eng. Sci. Technol. Rev., 3(1), pp. 36-40 (2010).

24. Siva Ranjani, G.I. and Ramamurthy, K. "Relative assessment of density and stability of foam produced with four synthetic surfactants", Mater. Struct., 43(10), pp. 1317-1325 (2010).

25. Singh, B., Ishwarya, G., Gupta, M., and Bhattacharyya, S.K. "Geopolymer concrete: a review of some recent developments", Const. Build. Mater., 85(15), pp. 78-90 (2015).

26. McGrath, P.F. and Hooton, R.D. "Re-evaluation of the AASHTO T259 90day salt ponding test", Cem. Concr. Res., 29(8), pp. 1239-1248 (1999).

27. Bernal, S.A., de Gutiérrez, R.M., and Provis, J.L. "Engineering and durability properties of concretes based on alkali-activated granulated blast furnace slag/metakaolin blends", Constr. Build. Mater., 33, pp. 99-108 (2012).

28. Ken, P.W., Ramli, M., and Ban, C.C. "An overview on the influence of various factors on the properties of geopolymer concrete derived from industrial byproducts", Constr. Build. Mater., 77, pp. 370-395 (2015).

29. Bakharev, T., Sanjayan, J.G., and Cheng, Y.B. "Нydration of slag activated by alkalis", J. Aust. Ceram. Soc., 34, pp. 195-200 (1998).

30. Yang, T., Yao, X., and Zhang, Z. "Quantification of chloride diffusion in fly ash-slag-based geopolymers by X-ray fluorescence (XRF)", Constr. Build. Mater., 69, pp. 109-115 (2014).

\section{Biographies}

Parthiban Kathirvel works as Assistant Professor in the School of Civil Engineering, SASTRA University, Thanjavur, India. He completed his BSc in Civil Engineering at SASTRA University in the year 2006, MSc in Computer Methods and Applications in Structural Engineering at Anna University in the year 2008, and MBA in Technology Management at Anna University in the year 2010. He is pursuing his $\mathrm{PhD}$ in the area of Geopolymer Concrete.

Saravana Raja Mohan Kaliyaperumal works as Associate Dean in the School of Civil Engineering, SASTRA University, Thanjavur, India. He has completed his BSc in Civil Engineering at Annamalai University in the year 1986, MSc in Structural Engineering at Annamalai University in the year 1989, and $\mathrm{PhD}$ at Bharathidasan University in the year 2006. $\mathrm{He}$ is working in the area of structural mechanics of reinforced concrete members. 